\title{
Coagulated region analysis in a microwave surgical device with temperature-dependent physical properties of tissue
}

\author{
Ryo Manago ${ }^{1}$ and Kazuyuki Saito ${ }^{2 a)}$
}

\begin{abstract}
In surgical devices, it is pointed out that tissues around these devices may experience thermal damage (coagulation). Therefore, evaluating the coagulated region generated by a microwave surgical device is an important issue. In this paper, we estimate the distribution of the coagulated region using numerical calculation. Then, there is a possibility that the calculated results will be affected by change to the electrical and thermal constants during heating. Therefore, the temperature dependence of the tissue was considered. As a result, it was confirmed that the coagulation width at the center of the lower blade was $0.5 \mathrm{~mm}$ larger than that without temperature dependence.

Keywords: microwave surgical device, coagulated region, physical properties of tissue

Classification: Microwave and millimeter-wave devices, circuits, and modules
\end{abstract}

\section{Introduction}

In modern surgery, surgical devices having multiple functions (e.g., tissue coagulation and tissue resection) are frequently used $[1,2,3,4]$. These devices contribute to shortening the operation time and suppressing the amount of bleeding [5, 6]. However, it is reported that thermal damage caused by surgical device occurs not only at the target site but also in the surrounding tissue $[7,8,9,10]$. Because thermal damage (coagulation) to neighboring organs may cause postoperative pain and serious complications $[11,12,13]$, it is necessary to evaluate the heating characteristic of tissues surrounding the device. Particularly, a microwave surgical device $[14,15,16]$ is a new device having insufficient survey data compared with conventional surgical devices (e.g., electrical scalpel). Therefore, evaluating the distribution of coagulated region generated by a microwave surgical device is an important issue.

Generally, biological tissue coagulates at approximately $60^{\circ} \mathrm{C}$ or higher $[17,18,19,20,21]$. However, when the heating time is longer, the biological tissue coagulates even if the temperature is less than $60^{\circ} \mathrm{C}$. To determine the distribution of the coagulated region, it is necessary to consider the relationship between temperature

\footnotetext{
${ }^{1}$ Graduate School of Science and Engineering, Chiba University, 1-33 Yayoi-cho, Inage-ku, Chiba 263-8522, Japan ${ }^{2}$ Center for Frontier Medical Engineering, Chiba University, 1-33 Yayoi-cho, Inage-ku, Chiba 263-8522, Japan

a) kazuyuki_saito@faculty.chiba-u.jp
}

DOI: 10.1587/elex.16.20190131

Received March 5, 2019

Accepted April 5, 2019

Publicized April 16, 2019

Copyedited May 10, 2019 and heating time. Using this relationship, in this study, distribution of tissue coagulated region generated by a microwave surgical device is calculated using a numerical calculation. Then, there is a possibility that the tissue in the coagulated region will be affected by changes to the tissue's physical properties during heating [22, 23, 24, 25]. Therefore, it is necessary to analyze the distribution of coagulated region with consideration of the temperature dependency of the tissue during heating. In this paper, we estimate the distribution of coagulated region depending on the changes to the electrical (relative permittivity and electrical conductivity) and thermal constants (specific heat and thermal conductivity).

\section{Temperature-dependent liver model}

In this analysis, the relationship between physical properties and water content ratio [26] was used. Endo et al. confirmed that physical properties (electrical constants, thermal constants) of tissue depend on the water content ratio [27]. The water content ratio of the sample is obtained by the ratio of the weight of the sample before and after drying. The water content ratio $R_{w}(T)$ between $43^{\circ} \mathrm{C}$ to $100{ }^{\circ} \mathrm{C}$ is expressed as a function of temperature, as follows:

$$
R_{w}(T)=-0.298 T+86.0
$$

where $T$ denotes the temperature of the tissue $\left[{ }^{\circ} \mathrm{C}\right]$. When the tissue's temperature is less than $43^{\circ} \mathrm{C}$, the water content ratio is approximately $73.2 \mathrm{wt} \%$ constant. In addition, the water content ratio at the maximum temperature of $100{ }^{\circ} \mathrm{C}$ is approximately $56.2 \mathrm{wt} \%$. Furthermore, in this previous study [27], the relationship between the water content ratio and physical properties of tissue was also investigated. The electrical (relative permittivity $\varepsilon_{r}$, and electrical conductivity $\sigma[\mathrm{S} / \mathrm{m}]$ ) and thermal constants (specific heat $c$, and thermal conductivity $\kappa$ ) are expressed by the following approximate expressions.

$$
\begin{aligned}
& \varepsilon_{r}\left(R_{w}\right)=69.58 \times 0.0006^{\exp \left(-0.0379 \times R_{w}\right)}+1.42 \\
& \sigma\left(R_{w}\right)=2.8 \times 0.0044^{\exp \left(-0.0344 \times R_{w}\right)} \\
& c\left(R_{w}\right)=3231 \times 0.21^{\exp \left(-0.0269 \times R_{w}\right)}+946 \\
& \kappa\left(R_{w}\right)=0.61 \times 0.26^{\exp \left(-0.0311 \times R_{w}\right)}
\end{aligned}
$$

These equations were obtained as an empirical approximate expression by measuring the relation between the water content ratio and each physical property value using por- 
cine liver. Because it uses porcine liver, it seems that the same tendency as these formulas appears in other organs such as muscles which has a water content similar to that of the liver. On the other hand, it is difficult to apply these formulas in tissues where water content ratio such as fat because it is significantly different from liver tissue. Surgical procedures to which these equations are applied include ablation therapy and hemostasis. In this calculation, the water content ratio and the dependent physical properties of tissue were modeled numerically using above relationships.

A flowchart of calculations is shown in Fig. 1. In this analysis, electromagnetic field analysis (i) and temperature analysis (ii) are repeated, as shown in Fig. 1. First, the distribution of the electrical field was calculated. Then, specific absorption rate (SAR) in the biological tissue was calculated from the electrical field using the following formula:

$$
\mathrm{SAR}=\frac{\sigma\left(R_{w}\right)}{\rho} E^{2}[\mathrm{~W} / \mathrm{kg}]
$$

where $\rho$ and $E$ are the mass density $\left[\mathrm{kg} / \mathrm{m}^{3}\right]$ and rootmean-square electrical field $[\mathrm{V} / \mathrm{m}]$ respectively. SAR corresponds to the amount of heat generated by the electric field. Using the SAR as a heat source, the temperature distribution is calculated. In the temperature analysis, two operations are performed. First, the water content ratio of each voxel is calculated from the tissue temperature. Using this water content ratio, thermal constants are calculated for each time step and updated. The second operation is determining whether the tissue was coagulated. The coagulation determination method refers to previous research [28]. According to this research, when the time required for a porcine liver to coagulate is $t_{c o}$ and the temperature of the porcine liver is $T\left[{ }^{\circ} \mathrm{C}\right], t_{c o}$ can be expressed by the following equation.
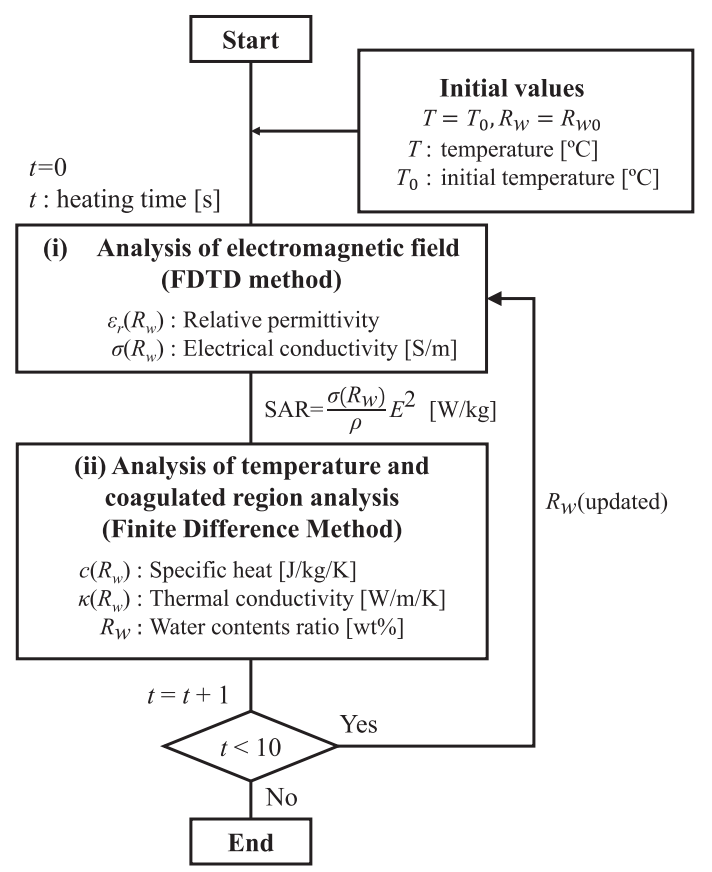

Fig. 1. Flowchart

$$
t_{c o}=-0.955 T+69.379
$$

Equation 7 shows that when the porcine liver is boiled at 50 to $70^{\circ} \mathrm{C}$, it is visually confirmed that the liver's color changes from red to white. The time until the color changes is measured as the time required for coagulation. Using this relationship, the coagulation degree for each time step was calculated from $t_{c o}$. Then, the coagulation degree of each time step is added up, and it is judged that the voxels whose total exceeds threshold are coagulated.

After completion of the temperature analysis for $1 \mathrm{~s}$, the electrical constants are calculated based on the water content ratio. Then, a second electromagnetic field analysis is performed using these electrical constants. Thereafter, this procedure is repeated until the total heating time is reached.

\section{Calculation model}

Fig. 2 shows the calculation model for electromagnetic field and temperature analysis. The analysis method uses the finite difference time domain (FDTD) method [29], and the calculated region is $60 \mathrm{~mm} \times 40 \mathrm{~mm} \times 70 \mathrm{~mm}$. Fig. 3 shows the tip structure of the device and view from lower side, while the model shows a scissors-type microwave surgical device grasping the liver tissue. This device has an antenna akin to a monopole antenna at the lower blade for tissue heating. The antenna (lower blade) and the upper blade were made to be perfect conductors, and the lower blade (antenna part) is covered with Teflon. The thickness of the liver tissue is $5 \mathrm{~mm}$, and the electrical constants of the liver tissue are shown in Table I. Cell size in the calculation region is composed of non-uniform cells, where the minimum cell size is $\Delta x=\Delta y=\Delta z=0.1 \mathrm{~mm}$ in the vicinity of the device, and the cell size is increased as it moves away from the device, with the maximum cell size

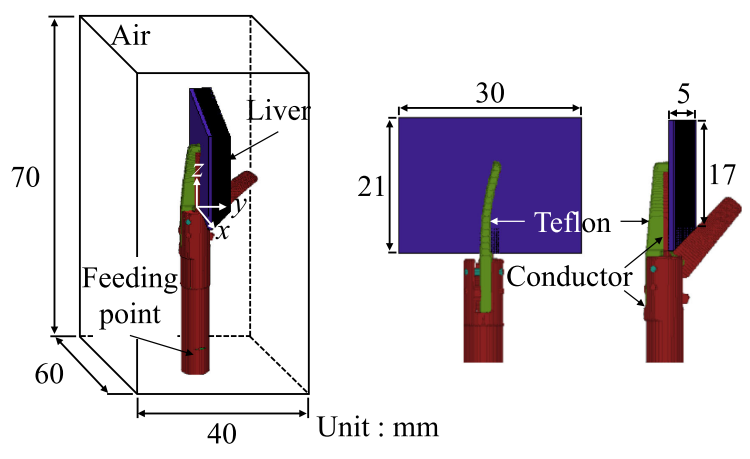

Fig. 2. Calculation model
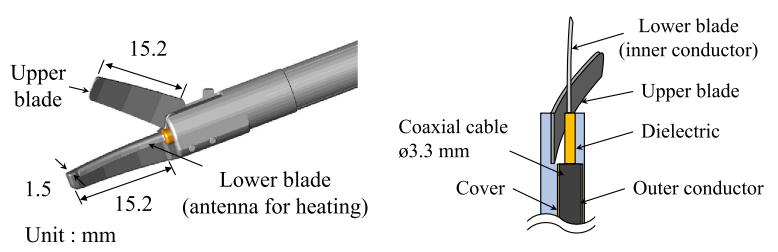

Fig. 3. Tip structure of device and view from lower side 
Table I. Electrical and thermal constants

\begin{tabular}{lc}
\hline Parameters & Liver \\
\hline Relative permittivity $\varepsilon_{r}$ & $30.2 \sim 45.2$ (from Eq. 2) \\
Electrical conductivity $\sigma[\mathrm{S} / \mathrm{m}]$ & $1.28 \sim 1.80$ (from Eq. 3) \\
Density $\rho\left[\mathrm{kg} / \mathrm{m}^{3}\right]$ & 1,079 [30] \\
Specific heat $c[\mathrm{~J} / \mathrm{kg} / \mathrm{K}]$ & $3,236 \sim 3,545$ (from Eq. 4) \\
Thermal conductivity $\kappa[\mathrm{W} / \mathrm{m} / \mathrm{K}]$ & $0.48 \sim 0.53$ (from Eq. 5) \\
\hline
\end{tabular}

being $\Delta x=\Delta y=\Delta z=0.5 \mathrm{~mm}$. For the absorption boundary condition, eight perfectly matched layers (PML) were applied and a microwave $(2.45 \mathrm{GHz})$ was fed to the coaxial cable at the edge of the device.

In the temperature analysis, the finite-difference method (FDM) was employed in the numerical calculation, and the approximation was based on [31]. The temperature of the air and of the device were kept at $25^{\circ} \mathrm{C}$. The initial tissue temperature was also $25^{\circ} \mathrm{C}$, and the maximum temperature was set to $100^{\circ} \mathrm{C}$. This is because moisture evaporates when the temperature reaches $100^{\circ} \mathrm{C}$, and the temperature increase stops. The thermal constants of the liver tissue are shown in Table I. The blood flow rate $F$ was set as 0 . This is because in the energy device used in surgeries, hemostasis is performed with the tissue being gripped. In addition, in large blood vessels, it is often the case that the ligation is cut off using clips. With these clips, blood flow in the hemostasis site stopped. Therefore, the blood flow rate was not considered in this analysis. The update interval is $1 \mathrm{~s}$ and total heating time is $10 \mathrm{~s}$. When the update interval is $2 \mathrm{~s}$ or less, it is confirmed that the change in coagulated region converges. The maximum radiation power is $42 \mathrm{~W}$, and the radiated power depends on the reflection coefficient at the feeding point.

\section{Results and discussion}

Fig. 4 shows the reflection coefficient vs. the heating time. In this calculation, radiation power depends on the reflection coefficient. From this graph, it can be seen that the reflection coefficient increases with heating. The reflection coefficient during a heating time of $0 \mathrm{~s}$ to $2 \mathrm{~s}$ is greatly increased when compared with other heating times. This result shows that the tissue's physical properties changed during that time. Fig. 5(a) shows the coagulated region without updated physical properties, and Fig. 5(b) shows the coagulated region with updated physical properties. It was confirmed that a change occurred in the coagulated region due to the tissue's temperature-dependent physical properties. In Table II, to investigate the difference in detail, the coagulation widths of the tip $(z=12.7 \mathrm{~mm})$, center $(z=7.1 \mathrm{~mm})$, and root $(z=1.6 \mathrm{~mm})$ of the blade were compared. For example, the coagulation width at the tip of the blade was defined as the coagulated length in the $x$ direction at $z=12.7 \mathrm{~mm}$. From Table II, it can be seen whether the physical properties were updated, as the coagulation width at the center of the lower blade was $0.5 \mathrm{~mm}$ larger than that without updated liver tissue. This difference cannot be ignored in precision surgery such as brain surgery. Otherwise, the coagulation width at the root of

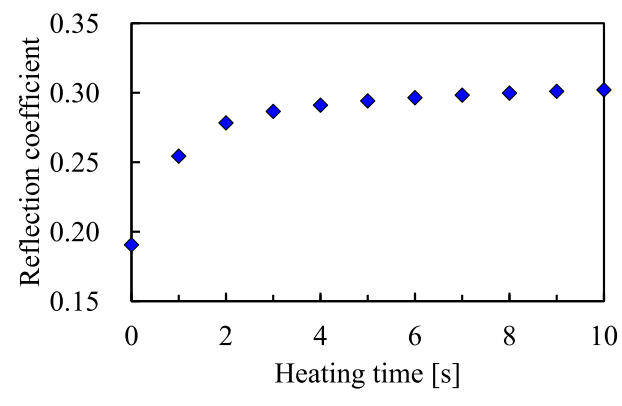

Fig. 4. Reflection coefficient vs. heating time

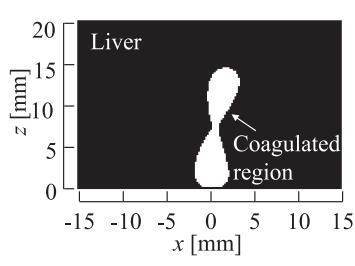

(a) Without updated

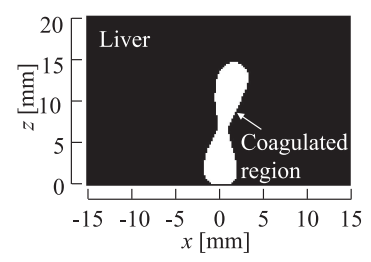

(b) With updated
Fig. 5. Coagulated region (lower blade contact surface)

Table II. Relationship between physical properties update and coagulation width

\begin{tabular}{cccc}
\hline & \multicolumn{3}{c}{ Coagulation width } \\
\cline { 2 - 4 } & Tip & Center & Root \\
\hline With updated & $3.4 \mathrm{~mm}$ & $1.2 \mathrm{~mm}$ & $3.8 \mathrm{~mm}$ \\
Without updated & $3.4 \mathrm{~mm}$ & $0.7 \mathrm{~mm}$ & $3.9 \mathrm{~mm}$ \\
\hline
\end{tabular}

the lower blade was $0.1 \mathrm{~mm}$ smaller than that without updated liver tissue. Because the relative permittivity decreases as the tissue is heated, the wavelength becomes longer than the length of the lower blade. Therefore, electric field around the lower blade develops a uniform distribution. For this reason, the rate of heating to the center of the lower blade increased, while the heating region at the root portion became narrower.

\section{Conclusion}

In this paper, a numerical model of the liver with temperature dependency was first created. Next, the coagulated region of the tissue with temperature dependence was calculated. As a result, it was confirmed that the coagulation width at the center of the lower blade was $0.5 \mathrm{~mm}$ larger than that without temperature-dependent physical properties. This difference may be problematic when there are important nerves in the vicinity such as in brain surgery. Therefore, when determining the distribution of coagulated region of such a surgery target, it is conceivable that an analysis that considers the tissue's temperature-dependent physical properties is necessary. By using the method of this paper, it is possible to simulate the coagulated region before the surgical operations. 


\section{References}

[1] N. K. Arvind, et al.: "Contemporary use of ultrasonic versus standard electrosurgical dissection in laparoscopic nephrectomy: Safety, efficacy and cost," Arab J. Urol. 16 (2018) 335 (DOI: 10. 1016/j.aju.2018.05.003).

[2] H. Yoshiki, et al.: "Surgical energy device using steam jet for robotic assisted surgery," Proc. 37th Annu. Int. Conf. IEEE Eng. Med. Biol. Soc. (2015) 6872 (DOI: 10.1109/EMBC.2015. 7319972).

[3] B. Aryal, et al:: "Evaluation of THUNDERBEAT ${ }^{\circledR}$ in open liver resection- A single-center experience," BMC Surg. 18 (2018) 86 (DOI: 10.1186/s12893-018-0423-2).

[4] K. Gallagher, et al.: "Electrosurgery," Surgery (Oxford) 29 (2011) 70 (DOI: 10.1016/j.mpsur.2010.11.009).

[5] R. Topaktas, et al.: "Effectiveness of harmonic scalpel in laparoscopic treatment of simple renal cyst," J. Pak. Med. Assoc. 68 (2018) 1124.

[6] G. Liao, et al:: "Harmonic scalpel versus monopolar electrocauterization in cholecystectomy," J. Soc. Laparoendosc. Surg. 20 (2016) e2016.00037 (DOI: 10.4293/JSLS.2016.00037).

[7] T. Azuma, et al.: "Evaluation of tonsillectomy with four different methods," Practica Oto-Rhino-Laryngologica 100 (2007) 743 (in Japanese) (DOI: 10.5631/jibirin.100.743).

[8] Z. Pogorelić, et al:: "Lateral thermal damage of mesoappendix and appendiceal base during laparoscopic appendectomy in children: Comparison of the harmonic scalpel (Ultracision), bipolar coagulation (LigaSure), and thermal fusion technology (MiSeal), J. Surg. Res. 212 (2017) 101 (DOI: 10.1016/j.jss.2017.01.014).

[9] T. Diamantis, et al.: "Comparison of monopolar electrocoagulation, bipolar electrocoagulation, ultracision, and Ligasure," 36 (2006) 908 (DOI: 10.1007/s00595-006-3254-1).

[10] Z. Perko, et al.: "Lateral thermal damage to rat abdominal wall after harmonic scalpel application," Surg. Endosc. 20 (2006) 322 (DOI: 10.1007/s00464-005-0089-6).

[11] D. Schneider, et al:: "Use of ultrasonic scalpel and monopolar electrocautery for skin incisions in neck dissection: A prospective randomized trial," Oral Maxillofacial Surg. 22 (2018) 169 (DOI: 10.1007/s10006-018-0686-x).

[12] F. M. B. Bisinotto, et al.: "Burns related to electrosurgery - Report of two cases," Rev. Bras. Anestesiol. 67 (2017) 527 (DOI: 10.1016/ j.bjane.2015.08.018).

[13] H.-Y. Huang, et al.: "Complications of electrosurgery in laparoscopy," Gynecol. Minimally Invasive Therapy 3 (2014) 39 (DOI 10.1016/j.gmit.2014.05.004).

[14] Z. P. Tsiamoulos, et al.: "A novel multimodality endoscopic device for colonic submucosal dissection using a combination of bipolar radiofrequency and microwave modalities," Endoscopy 48 (2016) 271 (DOI: 10.1055/s-0042-101344).

[15] Y. Endo, et al.: "The development of forceps-type microwave tissue coagulator for surgical operation," IEEE Trans. Microw. Theory Techn. 63 (2015) 2041 (DOI: 10.1109/TMTT.2015.2427154).

[16] T. Tani, et al.: "The invention of microwave surgical scissors for seamless coagulation and cutting," Surgery Today 48 (2018) 856 (DOI: 10.1007/s00595-018-1662-7).

[17] R. Chopra: "Image-guided thermal therapy (section31)," Biomedical Technology and Devices Handbook, eds. J. Moore and G. Zouridakis (CRC Press, Florida, 2003).

[18] H. Ai, et al.: "Temperature distribution analysis of tissue water vaporization during microwave ablation: Experiments and simulations," Int. J. Hyperthermia 28 (2012) 674 (DOI: 10.3109/ 02656736.2012.710769).

[19] W. M. Whelan, et al:: "A novel strategy for monitoring laser thermal therapy based on changes in optothermal properties of heated tissues," Int. J. Thermophys. 26 (2005) 233 (DOI: 10.1007/ s10765-005-2372-0).

[20] S. N. Goldberg, et al.: "Thermal ablation therapy for focal malignancy: A unified approach to underlying principles, techniques, and diagnostic imaging guidance," Am. J. Roentgenol. 174 (2000) 323 (DOI: 10.2214/ajr.174.2.1740323).

[21] B. W. Dong, et al.: "Sonographically guided microwave coagu- lation treatment of liver cancer: an experimental and clinical study," Am. J. Roentgenol. 171 (1998) 449 (DOI: 10.2214/ajr. 171.2.9694473).

[22] D. Yang, et al.: "Measurement and analysis of tissue temperature during microwave liver ablation," IEEE Trans. Biomed. Eng. 54 (2007) 150 (DOI: 10.1109/TBME.2006.884647).

[23] Y. Endo, et al:: "Dielectric properties and water contents of coagulated biological tissue by microwave heating," IEICE Commun. Express 4 (2015) 105 (DOI: 10.1587/comex.4.105).

[24] C. L. Brace: "Temperature-dependent dielectric properties of liver tissue measured during thermal ablation: Toward an improved numerical model," Proc. 30th Annu. Int. Conf. IEEE Eng. Med. Biol. Soc. (2008) 230 (DOI: 10.1109/IEMBS.2008.4649132).

[25] M. Lazebnik, et al.: "Ultrawideband temperature-dependent dielectric properties of animal liver tissue in the microwave frequency range," Phys. Med. Biol. 51 (2006) 1941 (DOI: 10.1088/00319155/51/7/022).

[26] J. K. Towns: "Moisture content in proteins: Its effects and measurement," J. Chromatogr. A 705 (1995) 115 (DOI: 10.1016/ 0021-9673(94)01257-F).

[27] Y. Endo, et al.: "Temperature analysis of liver tissue in microwave coagulation therapy considering tissue dehydration by heating," IEICE Trans. Electron. E99-C (2016) 257 (DOI: 10.1587/transele. E99.C.257).

[28] K. Saito and K. Ito: "Preliminary investigation of numerical estimation of coagulated region generated by interstitial microwave antenna," Int. J. Hyperthermia 33 (2017) 69 (DOI: 10.1080/ 02656736.2016.1220636).

[29] K. S. Yee: "Numerical solution of initial boundary value problems involving Maxwell's equations in isotropic media," IEEE Trans. Antennas Propag. AP-14 (1966) 302 (DOI: 10.1109/TAP.1966. 1138693).

[30] IT'IS foundation homepage, "Tissue properties," https://itis.swiss/ virtual-population/tissue-properties/database/.

[31] K. Saito, et al.: "Heating characteristics of array applicator composed of two coaxial-slot antennas for microwave coagulation therapy," IEEE Trans. Microw. Theory Techn. 48 (2000) 1800 (DOI: $10.1109 / 22.883857)$. 